\title{
Re: percutaneous nephrolithotomy—position, position, position!
}

\author{
Siavash Falahatkar ${ }^{1} \cdot$ Mojtaba Teimoori $^{1}$ (i) \\ Received: 1 February 2018 / Accepted: 10 February 2018 / Published online: 15 February 2018 \\ c) Springer-Verlag GmbH Germany, part of Springer Nature 2018
}

Best access to renal stone is the continuous challenging topic. Assessing the safety and efficacy of various and very different PCNL positions for the treatment of renal calculi remained interesting. Zhao et al. [1] in their worthy study reviewed different positions of PCNL techniques.

The review by Zhao et al. [1] mentioned that there is challenging drawbacks related to increased cardiopulmonary risks and better anesthesia control in prone percutaneous nephrolithotomy (PCNL) in comparison to supine PCNLs. Complete supine PCNL has some other advantages for example:

To our experience, renal upper pole calyces are accessible from subcostal approach by several techniques. To our practice, the superior calix access in complete supine PCNL from subcostal approach can prevent complications of intercostal access. One of the most common techniques in our department is renal displacement by lung hyperinflation which is done by anesthesiologists. Hyperinflation can displace kidneys remarkably in our clinical practice (and kidney hypermobility can exaggerate that movement); upper pole access in complete supine PCNL with this technique has minimal morbidity and eludes the need for a supracostal access [2].

In the paper, the authors mentioned about the limitation of supine PCNL and about the limitation of working space. However, in complete supine PCNL, there is no restriction for working and there is enough space for working and entering to kidney due to not using padded rolls or anything at all.

One of the most important advantages of supine PCNL is about evacuation of stone fragments during the surgery that facilitates extracting stone fragments and, perhaps, can make shorter operation time. In complete supine PCNL, interfering of metal density of bed edge is one of the disadvantages that can be solved easily by increasing the fluoroscope angle degree [3].

\section{Compliance with ethical standards}

Conflict of interest The authors declare no conflict of interest regarding the publication of this article.

\section{References}

1. Zhao Z, Fan J, Liu Y, de la Rosette J, Zeng G (2018) Percutaneous nephrolithotomy: position, position, position! Urolithiasis 46(1):79-86 (Epub 2017/11/23)

2. Falahatkar S, Enshaei A, Afsharimoghaddam A, Emadi SA, Allahkhah AA (2010) Complete supine percutaneous nephrolithotomy with lung inflation avoids the need for a supracostal puncture. J Endourol 24(2):213-218 (Epub 2009/12/31)

3. Falahatkar S, Moghaddam AA, Salehi M, Nikpour S, Esmaili F, Khaki N (2008) Complete supine percutaneous nephrolithotripsy comparison with the prone standard technique. J Endourol 22(11):2513-2517 (Epub 2008/12/03)
Mojtaba Teimoori

mojtaba_teimoori@yahoo.com

Siavash Falahatkar

falahatkar_s@yahoo.com

1 Urology Research Center, Razi Hospital, School of Medicine, Guilan University of Medical Sciences, Rasht, Iran 